\title{
Robot-assisted laparoscopic pyeloplasty: current status and future directions
}

\author{
This article was published in the following Dove Press journal: \\ Robotic Surgery: Research and Reviews \\ 20 February 2015 \\ Number of times this article has been viewed
}

\author{
Arash Akhavein \\ Vincent G Bird \\ Department of Urology, College \\ of Medicine, University of Florida, \\ Gainesville, FL, USA
}

Correspondence: Arash Akhavein Department of Urology, College of Medicine, University of Florida, I600 SW Archer Road, PO Box 100247, Gainesville, FL 32610, USA

Email arash.akhavein@urology.ufl.edu

Vincent G Bird

Department of Urology, Division of Minimally Invasive Surgery, College of Medicine, University of Florida, 1600 SW Archer Road, PO Box 100247, Gainesville, FL 32610-0247, USA

Tel +l 3522736870

Email vincent.bird@urology.ufl.edu
Abstract: Ureteropelvic junction obstruction is an impairment of urine flow across the ureteropelvic junction and warrants surgical treatment (pyeloplasty) when clinically significant. Pyeloplasty techniques have undergone significant evolution over time, but dismembered pyeloplasty remains the gold standard for treatment, offering excellent success rate and durable results coupled with low complications. With the advent of minimally invasive surgery (MIS), dismembered pyeloplasty has been performed via MIS since the 1990s, and currently more than half of all pyeloplasties are done in this manner in the US. MIS pyeloplasty has proven benefits that include smaller incisions, shorter hospital stay, reduced blood loss, and less postoperative analgesic requirement. Robot-assisted laparoscopic pyeloplasty (RLP) adds a shorter operative time, elimination of surgeon's hand tremor, and likely a shorter surgeon learning curve by providing wristed instruments and better vision for easier suturing. However, studies have shown RLP to be costlier, which can be ameliorated by higher patient throughput, minimizing surgeon learning curve, and possible future availability of other robotic systems, leading to competition and cost reduction. State-of-the-art robotic surgical developments include single-incision surgery, for which different options are currently available and more are being developed. These efforts will likely lead to development and popularization of new dedicated robotic single-site surgical platforms and solitary intracorporeal stems with deployable camera and instruments. These technological advances will inevitably be incorporated into pyeloplasty, resulting in reduced costs and availability of more surgical options in this area.

Keywords: ureteropelvic junction obstruction, laparoendoscopic single-site surgery, minimally invasive surgery

\section{Introduction}

Ureteropelvic junction obstruction (UPJO) is defined as a functionally significant impairment of urine flow from the renal pelvis across the UPJ to the proximal ureter. Patients usually present with symptoms of flank pain, Dietl's crisis, urinary tract infections, hematuria, and sometimes nephrolithiasis. Diagnosis may involve use of a number of anatomic imaging studies (ultrasonography, intravenous pyelography, retrograde pyelography, computed tomography-based urography, etc) and functional tests (diuretic radionuclide renography, rarely Whitaker test); however, advanced abdominal imaging and diuretic scintirenography are generally most reliable for establishing this diagnosis.

\section{Treatment options for UPJO}

Treatment of UPJO, should it be considered significant, is surgical. The spectrum of available options from least to most invasive include retrograde endopyelotomy 
(Holmium-YAG laser, Acucise ${ }^{\circledR}$ device: Applied Medical, Rancho Santa Margarita, CA, USA; or other devices), percutaneous antegrade endopyelotomy (cold knife or laser), the rarely performed endopyeloplasty, minimally invasive surgery (MIS) dismembered pyeloplasty (ie, laparoscopic or robot-assisted laparoscopic techniques), and what has long been considered the gold-standard procedure, namely open dismembered (Anderson-Hynes) pyeloplasty. These surgeries have different success rates, advantages, and risk of adverse effects associated with them. Open dismembered pyeloplasty has been widely accepted to have a very high success rate of $>90 \%$. $^{1}$ This high success rate has been shown to be long-lasting as well, with O'Reilly et $\mathrm{al}^{2}$ reporting a $96 \%$ success on follow-up diuretic renogram performed 6-19 ( mean $=10.6$ ) years after surgery.

\section{Evolution of treatment of UPJO}

More than a century ago, Trendelenburg described the first open surgical treatment for UPJO. Kuster performed such a procedure successfully half a decade later. Shortly after, Fenger advocated the application of the Heineke-Mickulicz principle to allow development of a larger luminal diameter to avoid development of strictures. Various other techniques evolved over time, with the more renowned ones including Foley Y-V plasty in the early 20th century, the Culp-deWeerd spiral flap, and the Scardino vertical flap in the mid-20th century. ${ }^{3}$ The "gold standard" dismembered pyeloplasty was described by Anderson and Hynes in $1951,{ }^{4}$ which initially was performed via an open approach through a flank incision and now is more commonly done via minimally invasive approaches. The tried and tested principles of a successful repair include mucosal coaptation, tension-free anastomosis, and tailoring of a redundant renal pelvis for proper funneling if needed.

The second half of the 20th century coincided with the advent of percutaneous and endourological techniques for treatment of UPJO. Endopyelotomy techniques were developed based on antegrade or retrograde full-thickness incision of the strictured UPJ via cold knife or laser, a principle that had been described earlier by Albarran. Prolonged stenting, as described before by Davis in 1943, was generally included as part of these procedures. Endopyeloplasty incorporated the "Fenger-plasty" principle with the use of laparoscopic shears and suturing devices in a percutaneous, antegrade fashion. ${ }^{3} \mathrm{At}$ the same time, MIS was becoming increasingly popular by the end of the 20th century, which eventually led to dismembered pyeloplasty being performed via a laparoscopic approach.

\section{Laparoscopic pyeloplasty and robot- assisted laparoscopic pyeloplasty}

The first published laparoscopic dismembered pyeloplasty cases date back to 1993, as reported by Kavoussi et $\mathrm{al}^{5}$ and Schuessler et al. ${ }^{6}$ Laparoscopic pyeloplasty (LP) adds the benefits of MIS, including smaller incisions, decreased postoperative pain, and shorter length of hospital stay, compared to the situation with open surgery. ${ }^{7}$ Recent epidemiological studies in the US have shown a 23 -fold increase in use of MIS pyeloplasty from 1998 to 2009, with minimally invasive pyeloplasty surpassing open pyeloplasty in $2008 .^{8}$

The da Vinci surgical robot (Intuitive Surgical, Sunnyvale, CA, USA) is a master-slave system that allows the surgeon to move the robotic instruments attached to the patient-side cart (slave) in real time from the surgical console (master), providing three-dimensional views and magnifications of $\times 10-12$ for the operating surgeon. This system's EndoWrist ${ }^{\circledR}$ instruments have the advantage of seven degrees of freedom over conventional laparoscopic instruments, which results in a more favorable surgeon learning curve and ease of suturing. The system also reduces hand tremors, albeit at the price of losing virtually all surgical tactile feedback.

A recently published robust systematic review and metaanalysis on MIS pyeloplasty shows virtually identical and very high success rates of about $95 \%$ for both laparoscopic and robot-assisted techniques. ${ }^{9}$ All series that are included in the analysis report very low complication rates that range between $8 \%$ and $9 \%$ for both modalities. The patient follow-up periods are somewhat limited, but acceptable (mostly 1 year or more) among the included series. Almost all results included in the meta-analysis are also based on objective functional outcomes (postoperative diuretic renogram), in addition to imaging studies and subjective findings. These results are likely reflective of the basic tenet that regardless of which of these two techniques is employed, sound surgical judgment and proper mucosa-to-mucosa apposition of the tissue is the critical factor in effecting a good result.

Multiple studies have proven the reduction in analgesic requirement, blood loss, and hospital stay with MIS pyeloplasty relative to open surgery. Avoiding a rather large and arguably more painful flank incision (requiring splitting of multiple muscle layers, thus causing more discomfort and potentially denervation of muscles, leading to a "flank bulge") improves cosmesis and patient comfort. MIS approaches also are proven to improve factors such as operative blood loss, postoperative analgesic requirements (with possible earlier 
return of bowel function), and a shorter hospitalization period, making them the default treatment in our era. ${ }^{9,10}$

The advantages of robot-assisted surgery over conventional laparoscopy include elimination of surgeon hand tremor, conceivably a shorter learning curve, especially for intracorporeal suturing because of the wristed instruments, and a shorter operative time. ${ }^{9,11}$ The shorter operative time for robot-assisted laparoscopic pyeloplasty (RLP) seems to be more and more prominent in recently published studies. This may reflect 1) the increasing availability of the da Vinci surgical system in the US and across the globe and 2) growing adoption of robot-assisted surgery over conventional laparoscopy. Published studies that compare LP versus RLP have mostly reported a shorter operative time with RLP, mainly in the 10- to 30-minute range. ${ }^{9-13}$ This difference may be thought to depend mainly on the surgeon's comfort level with laparoscopic suturing, which arguably is the rate-limiting step of the procedure. These studies do not show any significant difference between the two techniques in terms of length of stay in hospital, success rate, complications, and safety. The perioperative data and outcomes for RLP in recent reported case series with $>100$ patients are summarized in Table 1 .

Published cost analysis studies from different institutions have shown LP to be more cost-effective than RLP. Bhayani et $\mathrm{al}^{14}$ compared the four-port da Vinci RLP with standard LP at their institution and showed a clear cost advantage for LP, even after considering that they have a high-throughput robotic surgery program. All factors, including operating room setup and takedown time, required staff, and other standard parameters, were considered and included in the analysis. Extremely high volumes ( $>500$ cases/year) and relatively short in-room time $(<130$ minutes) were required to allow RLP to reach cost equivalence with LP. In another study, Gettman et $\mathrm{al}^{11}$ found RLP to be 2.7 times more costly than LP. This was due to the longer operative time, disposable consumable costs, and the costly da Vinci system's value depreciation. ${ }^{10,11}$ Strategies to ameliorate the higher cost issue with robotic surgery in general include high throughput (utilizing the robot more frequently) and minimizing the learning curve for the procedure.
As robotic surgical platforms have become more widely available and are more frequently utilized for different patient populations, application of robotic technology to pediatric surgery is being studied more frequently. Bansal et al ${ }^{15}$ reported outcomes of and complications from their urologic robotic surgery on 136 children (10 infants) who underwent a plethora of urologic procedures, including a large number of RLP procedures (66 patients). The median age was 80.5 months, with an overall complication rate of $8.1 \%$, which is comparable to rates in other published pediatric series and somewhat lower than that in adults. ${ }^{15}$ A multicenter study of 178 pediatric robotic surgical procedures (pyeloplasty and partial nephrectomy, among the three most common) in children weighing $<15 \mathrm{~kg}$ versus heavier children, with a median follow-up of 37 months, did not show increased complication rates or additional safety concerns for the former group. Authors report longer robot setup time but no overall difference in operating room time for smaller children and advocate exercising extra caution and ensuring proper robot setup in treatment for smaller children. ${ }^{16}$

\section{State-of-the-art surgical options and future efforts}

RLP is now commonly performed in many institutions. Common trocar configurations include a three- or, more commonly, four-port configuration depending on surgeon preference. These small incisions are associated with better cosmetic results and presumably less postoperative incisional pain. As of most recent times, there has been a trend in laparoscopic surgery toward fewer incisions and reduced incision size. This has resulted in the development of single-incision MIS approaches in the 21st century, including single-incision laparoscopic surgery (SILS), laparoendoscopic single-site surgery (LESS), and U-LESS when performed transumbilically. Various access devices that generally allow the insertion of three ports (usually $5-10 \mathrm{~mm}$ ) through a single small incision are marketed by different manufacturers. Examples include the GelPOINTTM (Applied Medical, Rancho Santa Margarita, CA, USA), the SILS ${ }^{\mathrm{TM}}$ port (Covidien, Dublin, Ireland), and various

Table I Perioperative parameters and outcomes for RLP series with $>100$ patients

\begin{tabular}{|c|c|c|c|c|c|c|c|}
\hline Study & $\begin{array}{l}\text { Number of } \\
\text { patients }\end{array}$ & $\begin{array}{l}\text { Mean age } \\
\text { (years) }\end{array}$ & $\begin{array}{l}\text { Mean OT } \\
\text { (minutes) }\end{array}$ & $\begin{array}{l}\text { Success } \\
\text { rate (\%) }\end{array}$ & $\begin{array}{l}\text { Mean LOS } \\
\text { (days) }\end{array}$ & $\begin{array}{l}\text { Median F/U } \\
\text { (months) }\end{array}$ & $\begin{array}{l}\text { Complications } \\
(\%)\end{array}$ \\
\hline Minnillo et $\mathrm{al}^{25}$ & 155 & 10.5 & 198.5 & 96.0 & 1.95 & 31.7 & II.0 \\
\hline Mufarrij et $\mathrm{al}^{26}$ & 140 & 38.5 & 217.0 & 95.7 & 2.10 & 29.0 & 10.0 \\
\hline Sivaraman et $\mathrm{al}^{27}$ & 168 & 37.6 & 134.9 & 97.6 & 1.50 & 39.0 & 6.6 \\
\hline
\end{tabular}

Abbreviations: F/U, follow-up; LOS, length of hospital stay; OT, operative time; RLP, robot-assisted laparoscopic pyeloplasty. 
Triport $^{\mathrm{TM}}$ devices (Olympus, Tokyo, Japan). Different laparoscopic instruments are utilized, which usually fall into the conventional rigid, articulating, or prebent rigid categories. The latter two groups are especially designed to counteract the limited triangulation and provide expanded intraoperative reach in addition to minimizing instrument clashes. Development of these techniques is still in a state of evolution and has been accompanied by the introduction of a wide array of instrumentation to further facilitate these procedures. A multitude of surgical procedures have been performed via the LESS approach, namely cholecystectomy, appendectomy, colectomy, sleeve gastrectomy, and gastric banding, among others. The ability to perform these procedures successfully likely relates to surgeon experience and degree of complexity of the tasks (ie, if suturing is involved) that are required as part of the procedure. To date, progressive adoption of these types of techniques generally using a single-site approach has been somewhat limited. Reasons may include the technical expertise (instrument manipulation usually more physically challenging) and time consumption associated with performance of these procedures. There exists uncertainty as to how much improvement in outcomes - outside of cosmesis - is gained, if at all.

In the urologic specialty, LESS and robot-assisted LESS (R-LESS) have been implemented in various surgeries, including nephrectomy (partial, simple, radical, and donor), nephroureterectomy, renal cyst decortication, cryoablation, sacral colpopexy, augmentation enterocystoplasty, prostatectomy, and pyeloplasty. ${ }^{17-19}$ R-LESS appears to provide the improved ergonomics and visualization of the da Vinci system to confront the physical limitations of LESS. Second-generation da Vinci robotic instruments have been designed specifically for R-LESS, which allow intracorporeal deployment and increase maneuverability. Moreover, curved robotic trocars and programming of the system to reverse the "reversed" configuration of the instruments and allowing the surgeon to control each of the instruments on screen with his or her ipsilateral hand control have been developed. ${ }^{20}$ Tobis et $\mathrm{al}^{21}$ have used the conventional da Vinci robotic scope and instruments inserted either through three separate fascial incisions in a $3 \mathrm{~cm}$ single umbilical skin incision or through the GelPort ${ }^{\mathrm{TM}}$ system (which is larger than the GelPOINT ${ }^{\mathrm{TM}}$, thus allowing passage of three robotic trocars and insufflation tubing) in an umbilical incision with the da Vinci $\mathrm{S}$ and $\mathrm{Si}$ robots to perform dismembered pyeloplasty on eight patients; they further report similar therapeutic outcomes as in RLP along with superior cosmetic results. There are currently few case series available that report the outcomes of R-LESS pyeloplasty, and their results are summarized in Table 2.

As the daVinci robot was not specifically designed for R-LESS, various other platforms are being developed in other countries and the US for this purpose. Examples include the SPRINT system (Single-port Laparoscopy Bimanual Robot) by the ARAKNES program (Array of Robots Augmenting the Kinematics of Endoluminal Surgery) in Europe; and a miniature single-port Insertable Robotic Effectors platform being developed in Vanderbilt University with a solitary stem that deploys the stereoscopic camera and snake-like instruments inside the body through a single $15 \mathrm{~mm}$ incision. ${ }^{22}$ These latter endeavors are still in a state of evolution but clearly evidence the interest and dedication being put forth in further improving MIS as it relates to pyeloplasty and other procedures.

Robotic pyeloplasty is not the only MIS field undergoing constant evolution. A recent trend in LP has been the introduction of "mini laparoscopic pyeloplasty" or mLP, which utilizes $3.5 \mathrm{~mm}$ working trocars and a $5 \mathrm{~mm}$ camera port. Published results in both adults ${ }^{23}$ and pediatric patients ${ }^{24}$ show no significant difference in operative duration or estimated blood loss, as well as similar complication rates for LP and mLP. In the adult series, mLP was in fact associated with a shorter hospital stay and patients were more satisfied in the mLP group. Significantly improved cosmetic results (especially in children) by reduction of the incision size to $3 \mathrm{~mm}$ (from $8 \mathrm{~mm}$ to $10 \mathrm{~mm}$ in RLP, or $3 \mathrm{~cm}$ in various R-LESS techniques) and the significantly lower cost of mLP, compared to robotic options, make $\mathrm{mLP}$ more attractive and provide a significant growth potential.

\section{Conclusion}

Minimally invasive dismembered pyeloplasty has gained vast popularity as the surgical treatment of choice for UPJO.

Table 2 Perioperative parameters and outcomes for R-LESS pyeloplasty series

\begin{tabular}{llllllll}
\hline Study & $\begin{array}{l}\text { Number of } \\
\text { patients }\end{array}$ & $\begin{array}{l}\text { Mean age } \\
\text { (years) }\end{array}$ & $\begin{array}{l}\text { Mean OT } \\
\text { (minutes) }\end{array}$ & $\begin{array}{l}\text { Success } \\
\text { rate (\%) }\end{array}$ & $\begin{array}{l}\text { Mean LOS } \\
\text { (days) }\end{array}$ & $\begin{array}{l}\text { Median F/U } \\
\text { (months) }\end{array}$ & $\begin{array}{l}\text { Complications } \\
\text { (\%) }\end{array}$ \\
\hline Buffi et al ${ }^{28}$ & 30 & 39.0 & 170 & 93.3 & 5.6 & 13 & 26.0 \\
Tobis et al $^{21}$ & 8 & 22.0 & 181 & 100.0 & 1.6 & 39 & 12.5 \\
${\text { Olweny et al }{ }^{29}}^{2}$ & 10 & 40.3 & 226 & 100.0 & 2.6 & 4 & 10.0 \\
\hline
\end{tabular}

Abbreviations: F/U, follow-up; LOS, length of hospital stay; OT, operative time; R-LESS, robot-assisted laparoendoscopic single-site surgery. 
More than half of pyeloplasty procedures in the US are performed in this manner. Important advantages such as less postoperative morbidity and analgesic requirement, shorter hospital stay, and less blood loss, combined with excellent success rate and durable outcomes, have made this transition possible. Robotic surgical platforms (da Vinci) have provided surgeons with better visualization and better ergonomics, helping tremendously with intracorporeal suturing, which plays a main role in pyeloplasty. These factors, combined with increasing availability of this system in many hospitals globally and across the US and the growing numbers of urologic surgeons who possess robotic surgical skill, will lead to expanding utilization of RLP over LP. Despite lack of tactile feedback and the fact that RLP is clearly costlier than LP, the aforementioned factors are still likely to result in a paradigm shift. Efforts to mitigate the higher costs of RLP are likely to continue. Recent studies, albeit with limited available data, report that the use of RLP is safe in children and even smaller children/infants.

Development of single-incision laparoscopic and robotic techniques, paired with the ever-present demand for improved cosmesis and reduced incisions, has found its way into the urologic surgical realm. R-LESS pyeloplasty series have been reported during the past few years, with acceptable results and complication rates. As this technology is still in the early phases of both development and application, the number of patients in these series remains small, and major multi-institutional studies are lacking to provide robust evidence for validation of these outcomes. With the development and advent of new dedicated R-LESS platforms, we are likely to witness their incorporation into pyeloplasty, resulting in reduced costs through competition, in addition to availability of more surgical options in this area.

\section{Disclosure}

The authors report no conflicts of interest in this work.

\section{References}

1. Brooks JD, Kavoussi LR, Preminger GM, Schuessler WW, Moore RG. Comparison of open and endourologic approaches to the obstructed ureteropelvic junction. Urology. 1995;46:791-795.

2. O'Reilly PH, Brooman PJ, Mak S, et al. The long-term results of Anderson-Hynes pyeloplasty. BJU Int. 2001;87(4):287-289.

3. Singh I, HemalAK. Robot-assisted laparoscopic pyeloplasty. In: HemalAK, Menon M, editors. Robotics in Genitourinary Surgery. London: Springer; 2011:445-465.

4. Anderson JC, Hynes W. Plastic operation for hydronephrosis. Proc $R$ Soc Med. 1951;44(1):4-5.

5. Kavoussi LR, Peters CA. Laparoscopic pyeloplasty. J Urol. 1993; 150(6):1891-1894.

6. Schuessler WW, Grune MT, Tecuanhuey LV, Preminger GM. Laparoscopic dismembered pyeloplasty. J Urol. 1993;150(6): 1795-1799.
7. Bansal P, Gupta A, Mongha R, et al. Laparoscopic versus open pyeloplasty: comparison of two surgical approaches - a single centre experience of three years. J Minim Access Surg. 2008;4:76.

8. Jacobs BL, Kaufman SR, Morgenstern H, Hollenbeck BK, Wolf JS Jr, Hollingsworth JM. Trends in the treatment of adults with ureteropelvic junction obstruction. J Endourol. 2013;27(3):355-360.

9. Autorino R, Eden C, El-Ghoneimi A, et al. Robot-assisted and laparoscopic repair of ureteropelvic junction obstruction: a systematic review and meta-analysis. Eur Urol. 2014;65(2):430-452.

10. Boylu U, Basatac C, Turan T, Onol FF, Gumus E. Comparison of surgical and functional outcomes of minimally invasive and open pyeloplasty. $J$ Laparoendosc Adv Surg Tech A. 2012;22(10):968-971.

11. Gettman M, Peschel R, Neururer R, Bartsch G. A comparison of laparoscopic pyeloplasty performed with the da Vinci robotic system versus standard laparoscopic techniques: initial clinical results. Eur Urol. 2002;42(5):453-457.

12. Link RE, Bhayani SB, Kavoussi LR. A prospective comparison of robotic and laparoscopic pyeloplasty. Ann Surg. 2006;243(4): 486-491.

13. Braga LHP, Pace K, DeMaria J, Lorenzo AJ. Systematic review and meta-analysis of robotic-assisted versus conventional laparoscopic pyeloplasty for patients with ureteropelvic junction obstruction: effect on operative time, length of hospital stay, postoperative complications, and success rate. Eur Urol. 2009;56:848-858.

14. Bhayani SB, Link RE, Varkarakis JM, Kavoussi LR. Complete da Vinci versus laparoscopic pyeloplasty: cost analysis. J Endourol. 2005;19: 327-332.

15. Bansal D, Defoor WR Jr, Reddy PP, Minevich EA, Noh PH. Complications of robotic surgery in pediatric urology: a single institution experience. Urology. 2013;82(4):917-920.

16. Ballouhey Q, Villemagne T, Cros J, et al. A comparison of robotic surgery in children weighing above and below $15.0 \mathrm{~kg}$ : size does not affect surgery success. Surg Endosc. Epub December 6, 2014.

17. Kallidonis P, Kontogiannis S, Kyriazis I, et al. Laparoendoscopic single-site surgery in kidney surgery: clinical experience and future perspectives. Curr Urol Rep. 2013;14(5):496-505.

18. Kaouk JH, Goel RK, Haber GP, Crouzet S, Stein RJ. Robotic single-port transumbilical surgery in humans: initial report. BJU Int. 2009;103(3): 366-369.

19. Autorino R, Stein RJ, Lima E, et al. Current status and future perspectives in laparoendoscopic single-site and natural orifice transluminal endoscopic urological surgery. Int J Urol. 2010;17(5):410-431.

20. Cestari A, Buffi NM, Lista G, et al. Feasibility and preliminary clinical outcomes of robotic laparoendoscopic singlesite (R-LESS) pyeloplasty using a new single-port platform. Eur Urol. 2012;62:175-179.

21. Tobis S, Houman J, Thomer M, Rashid H, Wu G. Robot-assisted transumbilical laparoendoscopic single-site pyeloplasty: technique and perioperative outcomes from a single institution. J Laparoendosc Adv Surg Tech A. 2013;23(8):702-706.

22. Autorino R, Kaouk JH, Stolzenburg JU, et al. Current status and future directions of robotic single-site surgery: a systematic review. Eur Urol. 2013;63(2):266-280.

23. Fiori C, Morra I, Bertolo R, Mele F, Chiarissi ML, Porpiglia F. Standard vs mini-laparoscopic pyeloplasty: perioperative outcomes and cosmetic results. BJU Int. 2013;111(3 pt B):E121-E126.

24. Simforoosh N, Abedi A, Hosseini Sharifi SH, et al. Comparison of surgical outcomes and cosmetic results between standard and mini laparoscopic pyeloplasty in children younger than 1 year of age. J Pediatr Urol. 2014;10(5):819-823.

25. Minnillo BJ, Cruz JA, Sayao RH, et al. Long-term experience and outcomes of robotic assisted laparoscopic pyeloplasty in children and young adults. J Urol. 2011;185:1455-1460.

26. Mufarrij PW, Woods M, Shah OD, et al. Robotic dismembered pyeloplasty: a 6-year, multi-institutional experience. J Urol. 2008;180: 1391-1396.

27. Sivaraman A, Leveillee RJ, Patel MB, et al. Robot-assisted laparoscopic dismembered pyeloplasty for ureteropelvic junction obstruction: a multi-institutional experience. Urology. 2012;79:351-355. 
28. Buffi NM, Lughezzani G, Fossati N, et al. Robot-assisted, single-site, dismembered pyeloplasty for ureteropelvic junction obstruction with the new da Vinci Platform: a stage 2a study. Eur Urol. 2015;67(1): $151-156$.
29. Olweny EO, Park SK, Tan YK, Gurbuz C, Cadeddu JA, Best SL. Perioperative comparison of robotic assisted laparoendoscopic singlesite (LESS) pyeloplasty versus conventional LESS pyeloplasty. Eur Urol. 2012;61:410-414.

Robotic Surgery: Research and Reviews

Dovepress

\section{Publish your work in this journal}

Robotic Surgery: Research and Reviews is an international, peer reviewed, open access, online journal publishing original research, commentaries, reports, and reviews on the theory, use and application of robotics in surgical interventions. Articles on the use of supervisory-controlled robotic systems, telesurgical devices, and shared-control systems are includes a very quick and fair peer review system, which is all easy to use. Visit http://www.dovepress.com/testimonials.php to read real quotes from published authors. 